\title{
Bovine $\kappa$-Casein Gene Promoter Haplotypes with Potential Implications for Milk Protein Expression
}

\author{
A. F. Keating, ${ }^{\star} \dagger^{1}$ P. Davoren, ${ }^{\star 1}$ T. J. Smith, $\neq$ R. P. Ross, $\dagger$ and M. T. Cairns ${ }^{\star 2}$ \\ *National Diagnostics Centre, and \\ $\ddagger$ National Centre for Biomedical Engineering Science, National University of Ireland, Galway, Ireland \\ †Teagasc Dairy Products Research Centre, Moorepark, Fermoy, Co. Cork, Ireland
}

\section{ABSTRACT}

Genetic analysis of the $\kappa$-casein gene (CSN3) promoter regions of 42 cattle representing 9 different breeds revealed that 2 distinct haplotypes (A and $\mathrm{B}$ ) exist at this locus, differing from each other by single base changes at positions $-514(\mathrm{~T} / \mathrm{G}),-426(\mathrm{~T} / \mathrm{C})$, and -384 (T/C), where haplotype A has bases T, T, and T and haplotype $\mathrm{B}$ has bases $\mathrm{G}, \mathrm{C}$, and $\mathrm{C}$. The AA and $\mathrm{AB}$ haplotypes were found to occur at a higher frequency in the animals tested, with 69.0 and $21.4 \%$ being homozygous and heterozygous, respectively. The sequences that include these polymorphisms are potentially important in transcriptional regulation of the $\kappa$-casein gene, because they contain putative sites for binding of many transcription factors. Linkage disequilibrium between the $\kappa$-casein promoter haplotype and either one of the 2 major $\kappa$-casein coding sequence haplotypes was not evident. The A allele is dominant in all groups (dairy, beef, and dual purpose) with an allele frequency of $80 \%$ and is higher among high-yielding dairy animals (88.9\%) than among beef animals (75\%). The AB haplotype is comparatively rare in the dairy cattle $(11.1 \%)$ compared with both beef and dual-purpose animals. The BB haplotype, though rare overall $(9.5 \%)$, is much higher in dual-purpose animals (18.8\%) than dairy (5.6\%) animals. In contrast, the B allele is much more representative of the $\kappa$-casein promoters from other ruminants.

Key words: $\kappa$-casein, promoter haplotype, expression study

\section{INTRODUCTION}

The bovine $\kappa$-CN gene (CSN3) consists of 5 exons distributed over approximately $13 \mathrm{~kb}$ of the bovine ge-

Received October 18, 2006.

Accepted May 25, 2007.

${ }^{1}$ The first 2 named authors contributed equally to this paper and should be considered joint first authors.

${ }^{2}$ Corresponding author: michael.cairns@nuigalway.ie nome (Alexander et al., 1988; Martin et al., 2002). Eleven genetic haplotypes of $\kappa$-CN have been identified to date that differ in the coding region (Farrell et al., 2004). The 2 most common genetic haplotypes, designated $\mathrm{A}$ and $\mathrm{B}$, differ in 2 positions at codons 136 (AThr: B-Ile) and 148 (A-Asp: B-Ala) of exon 4 (Mercier et al., 1973; Ron et al., 1994) and can be distinguished by an RFLP-PCR reaction (Nierop Groot et al., 1995). Milk from BB cows reportedly contains higher amounts of protein (Ng-Kwai-Hang et al., 1984; Ron et al., 1994; Bobe et al., 1999) and is associated with shorter rennet coagulation time, firmer curd, and higher cheese yield than milk from AA animals (Schaar, 1984; Marziali and Ng-Kwai-Hang, 1986; Martin et al., 2002).

Many studies have been carried out to analyze the promoter region of the $\kappa$-CN gene. Coding sequence associated allele-specific polymorphisms have been identified in the distal promoter regions at positions -2035 (G/T), -1651 (A/T), and -999 (-/T) (Robitaille et al., 2005). Fifteen single nucleotide changes were identified in 13 cows from 7 different breeds in a study by Schild et al. (1994), and a DdeI RFLP within a 214-bp fragment of the $\kappa$-CN promoter has also been identified (Kaminski, 1996). Although these polymorphisms have been noted in the $\kappa$-CN gene promoter, it is unclear whether they are characteristic of a distinct haplotype or if they play a functional role by modulating gene expression.

In this study, polymorphism occurrence in the $\kappa$-CN gene promoter and the potential effect on transcriptional activity of the promoter were investigated. The bovine breeds chosen were considered representative of the Irish herd and included dairy, dual-purpose, and nondairy (beef) breeds. Potential links between promoter polymorphisms and the 2 most common coding sequence genetic polymorphisms were also investigated.

\section{MATERIALS AND METHODS}

\section{Blood Sampling and DNA Extraction}

Approximately $15 \mathrm{~mL}$ of blood was collected into heparinized tubes from the coccygeal vein of 42 cattle repre- 
Table 1. Primers used in this study

\begin{tabular}{llc}
\hline & \multicolumn{1}{c}{ Sequence $^{1}$} & $\begin{array}{c}\text { Melting } \\
\text { temperature, } \\
\text { Primer }\end{array}$ \\
\hline pAK06 & CGGAATTCTGGGCATATAAAAGATGG \\
pAK08 & AACTGCAGCTAAAAGCCAAAAGGAAGAAAAT & 69.2 \\
pAK20 & CGCGCTGCAGTATTTGATATGGGGAATGTTCAGGCTCA & 69.2 \\
pAK21 & CGCGCTCGAGTCCACTGTAAGGAACACCCAGGTAAAT & 72.7 \\
pAK22 & CGCGCTGCAGCTCGTGTTAGCAGTTTGGAAATTCT & 73.8 \\
pAK23 & CGCGCTCGAGTGGAATGCAGAGGAGGAAATAGAGTTGT & 71.8 \\
pAKp1 & TGAGCAGGTATCCTAGTTATGGACT & 73.8 \\
pAKp4 & GTCTTCTTTGATGTCTCCTTAGAG & 62.8 \\
pGLAK1 & GCGCACGCGTGCATATAAAAGATGGTCAG & 59.9 \\
pGLAK2 & GCGCACGCGTGAAGAAAGGGGAATCCTCC & 68.1 \\
pGLAK3 & GCGCACGCGTCTCGTGTTAGCAGTTTGGAAATTC & 72.3 \\
pGL3for & CTAGCAAAATAGGCTGTCCC & 71.9 \\
pGL3rev & TATGTTTTTGGCGTCTTCC & 57.3 \\
\hline
\end{tabular}

${ }^{1}$ Restriction site sequences: $\mathrm{CTGCAG}=P s t \mathrm{I}, \mathrm{CTCGAG}=$ XhoI, ACGCGT $=M l u \mathrm{I}$.

senting 9 breeds. Breeds sampled were high genetic merit Holstein-Friesian, low genetic merit HolsteinFriesian (Kennedy et al., 2003), Irish-Friesian, DutchFriesian, Limousin, Montbeliarde, Charolais, Normande, Norwegian Red, and Kerry. With the exception of the Limousin, Charolais, and Kerry animals, these animals were all part of the extended herd at Teagasc, Moorepark, Fermoy, Co. Cork. Limousin and Charolais samples were from Teagasc, Grange, Co. Meath, and Kerry samples were obtained from Duchas, Muckross House, Killarney, Co. Kerry. Blood samples were obtained for all animals, and DNA extractions were carried out using the Gentra capture column (Qiagen Ltd., Crawley, UK) system for approximately $200 \mu \mathrm{L}$ of whole blood per animal. Blood was stored at $-80^{\circ} \mathrm{C}$, and DNA was stored at $-20^{\circ} \mathrm{C}$ until further use.

\section{Primer Design}

Primers were designed as in Table 1 and synthesized by MWG Biotech (Ebersberg, Germany).

\section{PCR}

Polymerase chain reaction was carried out from a starting template of approximately $200 \mathrm{ng}$ of genomic DNA in a final volume of $50 \mu \mathrm{L}$ containing $1 \times$ Taq DNA polymerase buffer (Invitrogen, Carlsbad, CA), $1.5 \mathrm{mM}$ $\mathrm{MgCl}_{2}, 200 \mu M$ deoxynucleoside triphosphates (Promega, Madison, WI), $0.3 \mu M$ each primer, and $1 \mathrm{U}$ of Taq polymerase (Invitrogen). The reaction was amplified for 35 cycles. An initial incubation at $95^{\circ} \mathrm{C}$ for 2 min was followed by 35 cycles of $95^{\circ} \mathrm{C}$ for $1 \mathrm{~min}$, annealing temperature (Ta) for $1 \mathrm{~min}$, and $72^{\circ} \mathrm{C}$ for $1 \mathrm{~min}$ (annealing was carried out at $2^{\circ} \mathrm{C}$ below the melting temperature specific for each primer pair). Cycling was performed in a DNA engine thermal cycler (MJ Research, Waltham,
MA). Two constructs were designed, and the corresponding fragments for both the A and B haplotypes were amplified from the genomic DNA of homozygous animals by PCR using a proofreading Taq polymerase. The primers pAK20 and pAK21 incorporated restriction enzyme sites for PstI and XhoI, respectively, allowing cloning into the plasmid pCMVtkLUC. Six AK constructs (AK1 to AK3 for each allele) were subsequently amplified from the 2 purified plasmid templates and cloned into a luciferase reporter vector pGL3-Basic. Each fragment used the same downstream primer (pAK21, XhoI site) and 1 of the 3 upstream primers (pGLAK1 to pGLAK3) incorporating a MluI restriction site. All plasmids were sequenced on construction and again after many transfections. Primers pAK06, pAK08, and pAK20 to pAK24 were used to amplify $\kappa$ $\mathrm{CN}$ promoter fragments for sequencing. Primers pAKp1 and pAKp4 were used in PCR-RFLP to genotype $\kappa$-CN coding sequence variants.

\section{Restriction Digests}

Restriction digests were carried out in a final volume of $20 \mu \mathrm{L}$ containing $10 \mu \mathrm{L}$ of PCR product, $1 \times$ reaction buffer, and $1 \mathrm{U}$ of restriction enzyme. Restriction enzymes used for screening purposes were BclI and HindIII, and PstI, MluI, and XhoI were used for cloning purposes. Reactions were incubated at temperatures recommended by the manufacturer (Roche Diagnostics, Basel, Switzerland).

\section{Sequencing and Bioinformatics}

Sequencing of PCR products was carried out by MWG Biotech. The resulting sequences were analyzed using the Vector NTI suite of software (Invitrogen). Alignment of sequences for all 42 animals was carried out, 
and potential polymorphic sites were identified. Examination of chromatogram sequence files to confirm homozygotic and heterozygotic animals was also performed. Vector NTI was also used for promoter multispecies alignments: sequences aligned (with accession number) were bovine (M75887), yak (AF194988), goat (Z33882), horse (AY579426), mouse (AJ309571), rabbit (AJ309572), sheep (L31372), and water buffalo (AJ628346). MatInspector (Genomatix Software $\mathrm{GmbH}$, München, Germany) was used to identify potential transcription factor binding sites in the bovine promoter sequences (Professional 7.4.3 Jul. 2006; Cartharius et al., 2005).

\section{Generation of Truncated Promoter Luciferase Reporter Constructs}

Three promoter fragments of decreasing length were amplified for each haplotype using primers that incorporated restriction sites at their $5^{\prime}$ ends. Promoter fragments AK1, AK2, and AK3 were amplified with primers pGLAK1, pGLAK2, and pGLAK3, respectively, paired with pAK21 (Table 1) from a common plasmid for each haplotype. Fragment sizes were $505 \mathrm{bp}, 752 \mathrm{bp}$, and $1.3 \mathrm{~kb}$ and were designated pGLAK1, pGLAK2, and pGLAK3, respectively. Digestion was carried out to create compatible ends for subcloning into the pGL3-Basic (Promega) promoterless expression vector. Ligation reactions were transformed into TAM Ultracomp chemically competent Escherichia coli cells (Active Motif Europe, Rixensart, Belgium) as described by the manufacturer. All constructs were verified by sequencing using the pGL3for and pGL3rev sequencing primers (Table 1).

\section{Cell Culture}

Human mammary MCF7 cells (ATCC to HTB22) were cultured in Eagle's minimum essential medium (Invitrogen) containing 10\% (vol/vol) fetal bovine serum (Invitrogen) and 1\% (vol/vol) nonessential AA (Invitrogen). Cells were routinely passaged every 3 to $4 \mathrm{~d}$ by washing with PBS and treating with $3 \mathrm{~mL}$ of EDTAtrypsin (Sigma, St. Louis, MO) to remove adherent cells. Cells were maintained in a humidified incubator at $37^{\circ} \mathrm{C}$ and $5 \% \mathrm{CO}_{2}$. Cells were grown to $80 \%$ confluency and transiently cotransfected with luciferase reporter vectors using Fugene 6 transfection reagent (Roche Diagnostics). Four independent transfections were carried out. Six-well transfection plates were seeded at a concentration of $3 \times 10^{5}$ cells per well and incubated overnight at $37^{\circ} \mathrm{C}$ and $5 \% \mathrm{CO}_{2}$. Experimental constructs $(1 \mu \mathrm{g})$ were cotransfected with $100 \mathrm{ng}$ of pRLSV40 plasmid (Promega) to control for transfection efficiency. Forty-eight hours after transfection, media was removed from the wells, and $300 \mu \mathrm{L}$ of passive lysis buffer (Promega) was added. Following incubation at room temperature for $10 \mathrm{~min}$, samples were either assayed immediately as described below or stored at $-20^{\circ} \mathrm{C}$ for later analysis.

\section{Luciferase Assay}

The dual luciferase assay kit (Promega) was used to measure both Renilla and firefly luciferase expression by the reporter vectors on a Tecan Spectrafluor Plus luminometer using the Magellan software (Tecan UK Ltd., Reading, UK). Mean firefly luciferase activity values were corrected for variations in transfection efficiency using the corresponding mean Renilla luciferase values.

\section{Statistical Analysis}

Linkage disequilibrium of the promoter haplotype and coding sequence haplotype was analyzed by $\chi^{2}$ test: the null hypothesis was that no association existed between haplotypes. Statistical analysis of the reporter construct luciferase values was carried out using either the ANOVA function or individual $t$-test function of SPSS for Windows (Release 12.0.1, SPSS Inc., Chicago, IL).

\section{RESULTS}

\section{Amplification and Sequence Analysis of the $\kappa-C N$ Gene Promoter}

Nine bovine breeds that were considered representative of the Irish herd were chosen. Amplification and sequencing of the $\kappa$-CN promoter region $(2,072 \mathrm{bp})$ identified 3 polymorphic sites at positions $-514,-426$, and -384 (T/G, T/C, and T/C). The 3 single nucleotide polymorphisms (SNP) were found to be linked: animals were either homozygous or heterozygous for all 3 of the base variations, creating 3 promoter haplotypes, AA, $\mathrm{AB}$, or $\mathrm{BB}$. The base change from $\mathrm{T}$ to $\mathrm{C}$ at -426 destroys a recognition site for the restriction enzyme BclI, allowing a rapid screen for this base change and hence for the $\kappa$-CN promoter haplotypes (Figure 1). All animals were also genotyped for the SNP present in exon 4 of the $\kappa$-CN gene to determine whether a relationship exists between promoter haplotypes and the A and B major coding sequence haplotypes. The 2 major coding region haplotypes were again identified by restriction digestion: a 443-bp fragment was amplified and digested with restriction enzyme HindIII (Nierop Groot et al., 1995). Statistical analysis of these results using $\chi^{2}$ testing indicated that there was no apparent link between $\kappa$-CN promoter and coding sequence haplo- 
$\mathbf{A}$

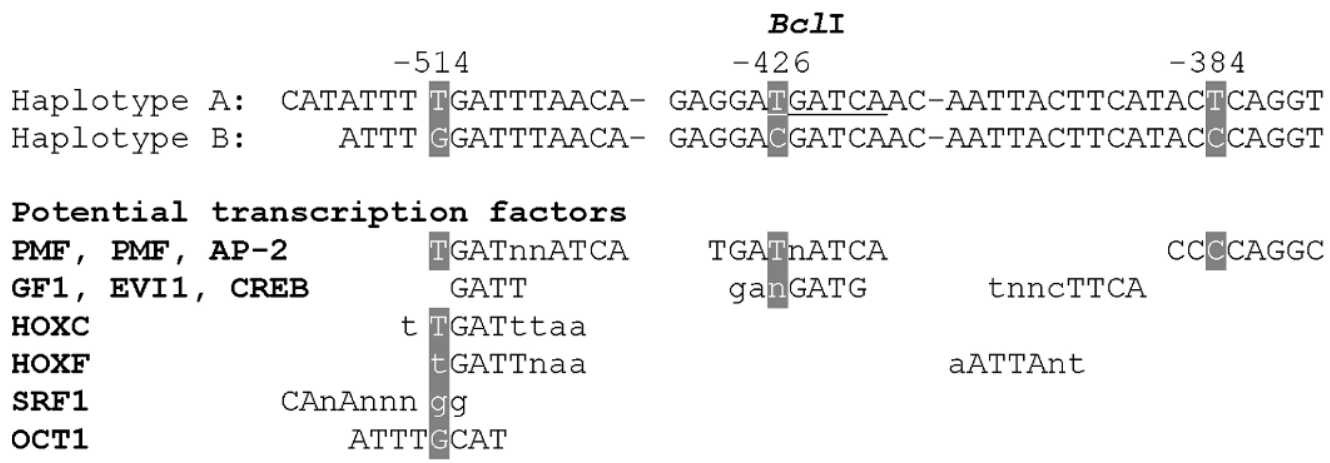

B

MGF

\begin{tabular}{|c|c|}
\hline e & A---GAGGATG \\
\hline & $------\mathrm{CTTCA}$ \\
\hline & $\mathrm{AC}---\mathrm{CTT}$ \\
\hline & $---\mathrm{CT}$ \\
\hline & IGACCAA----CTTG \\
\hline & ААACСАAТ---СТТАА \\
\hline & CCAAC---СТTCAT \\
\hline iffalo & $\begin{array}{l}\text { CGACCAAC---CTTCATACCCAGGTTCTT } \\
26\end{array}$ \\
\hline
\end{tabular}

C

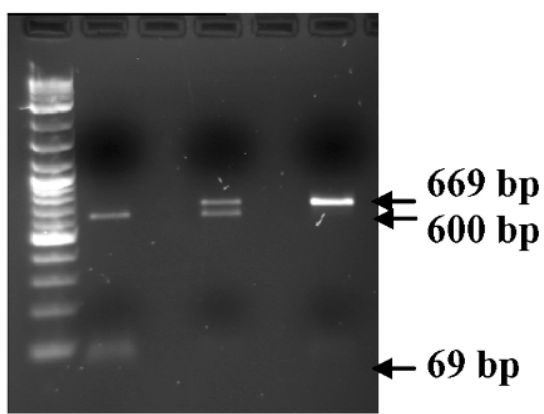

\section{AA AB BB}

Figure 1. Promoter haplotypes of $\kappa$-CN in relation to potential transcription factor binding sites. A. Haplotypes (A and B) in the bovine $\kappa$-CN promoter sequence are aligned across the 3 linked polymorphic sites (single nucleotide polymorphisms highlighted with white text in gray box). Transcription factor binding sites potentially affected by the polymorphism are given below the sequence, and the nucleotide position is indicated above the sequence. The $B c l$ I site used for the RFLP screen (see C) is marked. B. Alignment across the 3 linked polymorphic sites of $\kappa$-CN promoter sequences from other species (for accession numbers, see the materials and methods section). The neighboring MGF binding site is also marked in bold.

types A and $\mathrm{B}(P=0.89)$. These results, however, do not preclude the possibility that the promoter haplotypes are linked to other $\kappa$-CN coding sequence genetic haplotypes. The frequency of the $\mathrm{BB}$ coding region haplotype is known to be low, and this was confirmed here when a frequency of $4.7 \%$ among all animals was found. The B allele frequency was $19.4 \%$ in dairy breeds, $37.5 \%$ in dual-purpose breeds, and $31.3 \%$ in beef breeds. Although the A allele is the dominant allele in all groups of animals (dairy: $71.4 \%$; dual purpose: $62.5 \%$; beef: 
Table 2. $\kappa$-Casein coding sequence and promoter haplotypes

\begin{tabular}{|c|c|c|}
\hline Item & $\begin{array}{l}\text { Coding sequence } \\
\text { haplotype }\end{array}$ & $\begin{array}{l}\text { Promoter } \\
\text { haplotype }\end{array}$ \\
\hline \multicolumn{3}{|l|}{ Dairy } \\
\hline Holstein-Friesian & $\mathrm{AB}$ & AA \\
\hline Holstein-Friesian & AA & $\mathrm{AB}$ \\
\hline Holstein-Friesian & AA & AA \\
\hline Holstein-Friesian & $\mathrm{AB}$ & AA \\
\hline Holstein-Friesian & BB & AA \\
\hline Holstein-Friesian & AA & AA \\
\hline Holstein-Friesian & AA & AA \\
\hline Holstein-Friesian & AA & AA \\
\hline Irish-Friesian & $\mathrm{AA}$ & $\mathrm{AA}$ \\
\hline Irish-Friesian & AA & AA \\
\hline Irish-Friesian & $\mathrm{AB}$ & AA \\
\hline Irish-Friesian & $\mathrm{AB}$ & $\mathrm{BB}$ \\
\hline Norwegian Red & AA & $\mathrm{AB}$ \\
\hline Norwegian Red & $\mathrm{AA}$ & $\mathrm{AA}$ \\
\hline Dutch Friesian & AA & AA \\
\hline Dutch Friesian & AA & AA \\
\hline Dutch Friesian & AA & AA \\
\hline Dutch Friesian & $\mathrm{AB}$ & AA \\
\hline \multicolumn{3}{|l|}{ Allele frequency } \\
\hline A & 80.6 & 88.8 \\
\hline B & 19.4 & 11.1 \\
\hline \multicolumn{3}{|l|}{ Haplotype frequency } \\
\hline AA & 66.7 & 83.3 \\
\hline $\mathrm{AB}$ & 27.8 & 11.1 \\
\hline $\mathrm{BB}$ & 5.6 & 5.6 \\
\hline \multicolumn{3}{|l|}{ Dual purpose } \\
\hline Normande & $\mathrm{AB}$ & $\mathrm{AA}$ \\
\hline Normande & $\mathrm{BB}$ & AA \\
\hline Normande & $\mathrm{AB}$ & AA \\
\hline Normande & $\mathrm{AB}$ & AA \\
\hline Montbeliarde & AA & $\mathrm{BB}$ \\
\hline Montbeliarde & $\mathrm{AB}$ & AA \\
\hline Montbeliarde & $\mathrm{AB}$ & AA \\
\hline Montbeliarde & AA & $\mathrm{BB}$ \\
\hline Kerry & $\mathrm{AB}$ & $\mathrm{BB}$ \\
\hline Kerry & $\mathrm{AB}$ & AA \\
\hline Kerry & $\mathrm{AB}$ & $\mathrm{AB}$ \\
\hline Kerry & $\mathrm{AB}$ & $\mathrm{AB}$ \\
\hline Kerry & $\mathrm{AB}$ & AA \\
\hline Kerry & AA & AA \\
\hline Kerry & AA & $\mathrm{AB}$ \\
\hline Kerry & AA & AA \\
\hline \multicolumn{3}{|l|}{ Allele frequency } \\
\hline A & 62.5 & 71.9 \\
\hline $\mathrm{B}$ & 37.5 & 28.1 \\
\hline \multicolumn{3}{|l|}{ Haplotype frequency } \\
\hline AA & 31.3 & 62.5 \\
\hline $\mathrm{AB}$ & 62.5 & 18.8 \\
\hline $\mathrm{BB}$ & 6.3 & 18.8 \\
\hline \multicolumn{3}{|l|}{ Beef } \\
\hline Charolais & AA & $\mathrm{AB}$ \\
\hline Charolais & $\mathrm{AB}$ & AA \\
\hline Limousin & AA & AA \\
\hline Limousin & $\mathrm{AB}$ & $\mathrm{AB}$ \\
\hline Limousin & $\mathrm{AB}$ & AA \\
\hline Limousin & $\mathrm{AB}$ & $\mathrm{AB}$ \\
\hline Limousin & $\mathrm{AB}$ & AA \\
\hline Limousin & AA & $\mathrm{AB}$ \\
\hline \multicolumn{3}{|l|}{ Allele frequency } \\
\hline A & 68.8 & 75.0 \\
\hline $\mathrm{B}$ & 31.3 & 25.0 \\
\hline \multicolumn{3}{|l|}{ Haplotype frequency } \\
\hline $\mathrm{AA}$ & 37.5 & 50 \\
\hline $\mathrm{AB}$ & 62.5 & 50 \\
\hline $\mathrm{BB}$ & 0 & 0 \\
\hline
\end{tabular}

$68.8 \%$ ), the AA homozygote is only more frequent than the $\mathrm{AB}$ heterozygote in the dairy animals $(66.7 \%$ against $62.5 \%$ ), whereas in the nondairy animals, the $\mathrm{AB}$ heterozygote is nearly twice as frequent as the $\mathrm{AA}$ homozygote $(62.5 \%$ against $33.3 \%)$. This probably reflects the hybrid vigor of the dual-purpose animals compared with those specifically bred as high-yielding dairy animals.

The genetic haplotypes for the $\kappa$-CN gene promoter for all 42 animals screened are listed in Table 2. The frequencies of each haplotype of the $\kappa$-CN promoter were as follows: $\mathrm{AA}, 69 \%$; $\mathrm{AB}, 21.5 \%$; and $\mathrm{BB}, 9.5 \%$. The BB haplotype was therefore rare compared with the AA haplotype. In fact, the A allele frequency (80\%) was again dominant over the B allele frequency (20\%). When the breed differences were examined, the frequency of the A allele in dairy animals was $88.9 \%$ compared with $71.9 \%$ in the dual-purpose breeds and $75 \%$ in the beef breeds. It was interesting to note that although the allele frequency was similar for the beef and dual-purpose animals, the beef animals showed the greater heterozygosity (50\% as compared with $18.8 \%$ ).

\section{Functional Analysis of the $\kappa-C N$ Promoter Alleles}

Two constructs were designed, and the corresponding fragments for both the A and B haplotypes were amplified from the genomic DNA of homozygous animals by PCR using a proofreading Taq polymerase. Six AK constructs (AK1 to AK3 for each allele) were subsequently amplified from the 2 purified plasmid templates and cloned into the luciferase reporter vector pGL3-Basic. All plasmids were sequenced on construction and again after many transfections.

The MCF7 cells were transfected (using Fugene 6) with purified plasmid DNA preparations (endotoxinfree) of the 6 constructs together with a Renilla transfection efficiency control. Forty-eight hours after transfection, luciferase activity was measured using the dual luciferase assay kit. Activities were background-corrected and adjusted for transfection efficiency. Four independent transfections were carried out, and all values were presented as a percentage of the AK1-A value (Figure 2). The AK3 promoter fragment (1.3 kb), irrespective of haplotype, generally resulted in the highest luciferase expression of the 3 constructs. Statistically, both the AK3-A and AK3-B alleles were significantly higher than their AK1 counterparts $(P<0.05)$. In most instances ( 7 of 8 ), luciferase expression levels under the control of the AK3 promoter fragment were also higher than their corresponding AK2 allele in the same experiment, but statistical confirmation was lacking.

There were no significant differences detected between the 2 haplotypes in MCF7 cells, but both AK3- 


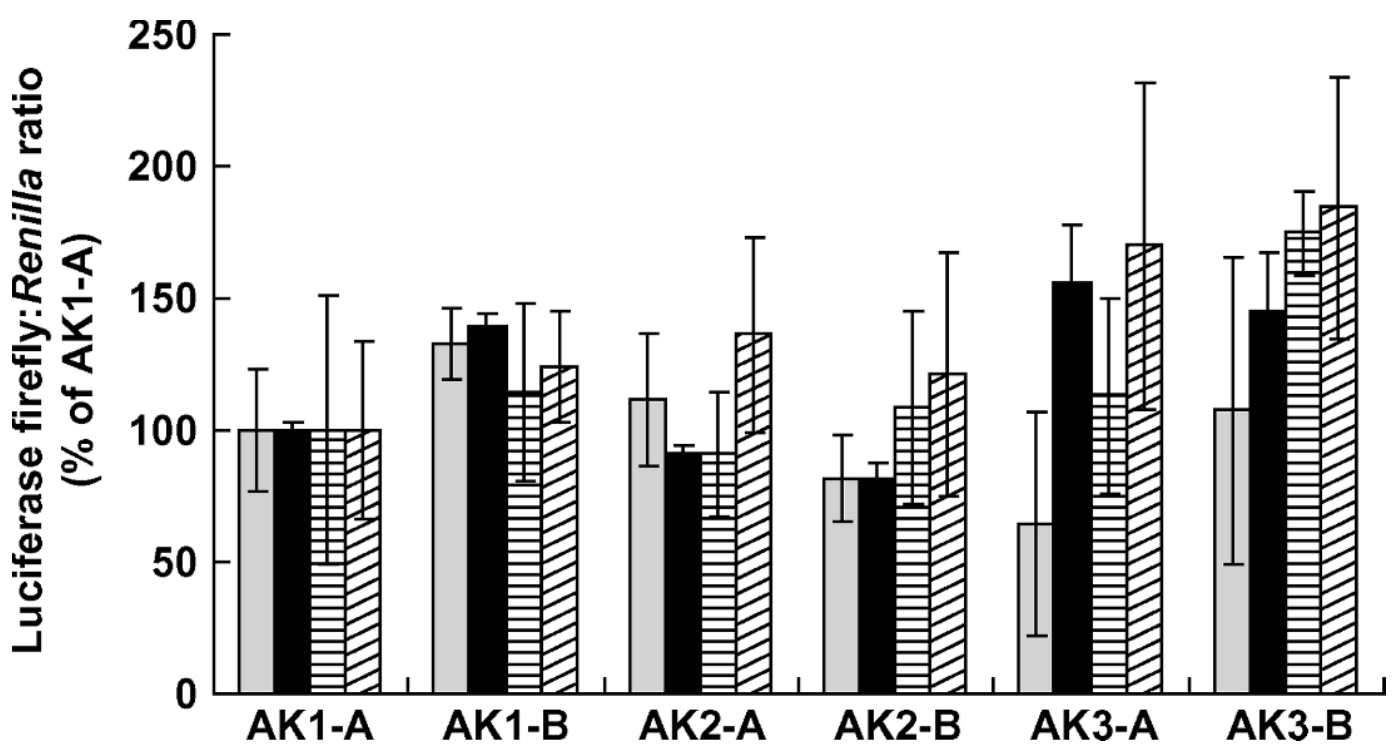

Figure 2. $\kappa$-Casein promoter activity in MCF7 cells. Plasmids AK1 (505-bp promoter), AK2 (752-bp promoter), and AK3 (1.3-kb promoter) of both haplotypes (A and B) carrying the firefly luciferase reporter under the control of the various $\kappa$-CN promoter fragments were transfected into MCF7 cells together with a Renilla luciferase control vector. Luciferase values were expressed as a ratio of firefly to Renilla and corrected to the AK1-A value (100\%). Results are from 4 independent experiments. Error bars show standard deviations for triplicates assayed in each experiment.

$\mathrm{B}$ and AK1-B were consistently higher (7 of 8 within experiment comparisons) than their AK3-A and AK1A counterparts. The closest significant difference was between the AK1-B allele and the AK1-A allele ( $P=$ $0.10)$.

\section{DISCUSSION}

Two haplotypes of the $\kappa$-CN promoter, differing in 3 nucleotide positions, have been identified. These nucleotide changes are present in regions of proposed importance for the regulation of the $\kappa$-CN gene expression. One of these base changes destroyed a recognition site for the restriction enzyme $B c l$ I, allowing a rapid screen by a PCR-RFLP method. Different frequency patterns for the A allele in dairy (88.8\%), dual-purpose (71.9\%), and beef $(75 \%)$ breeds were revealed. Animals were also screened for known genetic haplotypes in exon 4 of the coding sequence of the $\kappa$-CN gene; however, statistical analysis of both promoter and coding sequence haplotypes suggested that no linkage disequilibrium existed between the promoter and coding regions.

Putative transcription factor binding sites were identified in the $\kappa$-CN promoter sequence from both the literature and a search of transcription factor databases. The 3 polymorphic sites identified were in regions predicted to be of importance in the regulation of milk protein gene expression (Figure 1). Functional studies of the $\kappa$-CN promoter have been carried out previously in mouse cell lines (Rijnkels et al., 1995;
Adachi et al., 1996) and have provided evidence of pregnancy-specific and lactation-specific transcription factor binding sites in a segment of the promoter that includes the -384 and -426 polymorphic sites investigated in this study (Adachi et al., 1996). Expression of AK3 (approximately $1.3 \mathrm{~kb}$ of promoter) was found to be higher in MCF7 cells than expression of AK1 (approximately $500 \mathrm{bp}$ of promoter) irrespective of haplotype. This would be consistent with the reported presence of 2 crucial MGF-STAT5 binding sites highly conserved in 6 species in the additional stretch of promoter (Gerencser et al., 2002). Similar experiments were carried out in triplicate in $\mathrm{CHO}$ cells (data not shown): although there were no significant differences between the different-sized fragments of each allele, AK1 tended to be stronger than AK3 (opposite that of MCF7 cells), and AK1-A was significantly greater than AK2-B. The tissue-specific nature of the activation factor in the longer AK3 fragment is therefore borne out by the absence of activation in CHO-K1 cells. It is also in agreement with recent findings that a 2,040-bp $\kappa-\mathrm{CN}$ promoter fragment was stronger than a 925-bp promoter fragment (Debeljak et al., 2005).

Three linked polymorphisms have been identified in the promoter of the bovine $\kappa$-CN gene. If these SNP occur within transcription factor binding sites, they may alter the expression of the cis-related transcript and ultimately could have effects on milk yield or milk fat and protein composition. All 3 polymorphisms were noted in a previous study (Schild et al., 1994), but there 
was no suggestion that these were linked in any of the breeds they investigated. The promoter constructs were all functional in MCF7 cells (and CHO cells), but although the promoter haplotypes did not reveal a significant difference between promoter haplotypes, there was some indication that expression from the haplotypes differed and that haplotype B was expressed more strongly than haplotype A in MCF7 cells.

At positions $1(-514)$ and $2(-426)$, there are reported (Schild et al., 1994) potential sites for binding of the transcription factor PMF (TGATN ${ }_{1-2} \mathrm{ATCA}$ ), although the sequences differ from the consensus with an $\mathrm{A}$ or a $\mathrm{C}$ instead of the $\mathrm{T}$ (marked in bold). In both positions, the B haplotype with a $\mathrm{G}$ (position 1) or a $\mathrm{C}$ (position 2) substitution at the (underlined) T position is likely to be less favorable for PMF binding than the A haplotype (Figure 1). Surprisingly, the A haplotype is unique at position 1 (T) among the published $\kappa$-CN promoter sequences (goat, sheep, horse, mouse, water buffalo, and rabbit), which without exception have the $\mathrm{B}$ haplotypelike $\mathrm{G}$ at this position. Of the published sequences, there is no consensus at position 2 , though all the ruminants in common with the $\mathrm{B}$ haplotype share the $\mathrm{C}$ at this position; the $\mathrm{T}$ is only seen in the A haplotype and the mouse sequence. It should be stated that although the literature on $\kappa$-CN suggests that the polymorphisms at positions 1 and 2 overlap with sites for the binding of transcription factor PMF, the evidence for this factor binding site comes from studies of the $\beta$-CN gene in the nonruminant mouse (Lee and Oka, 1992). Information on the sequence variations that bind this transcription factor is very scant, nor is it included in the major transcription factor databases.

At position 3, there is a reported potential AP-2 site (CCCCAGGC), as originally described by Mitchell et al. (1987) and mentioned in relation to $\kappa$-CN by Schild et al. (1994); however, only the inner 6 nucleotides of the 8 match (see Figure 1). In this case, haplotype B (ACCCAGGT) is expected to bind more tightly than haplotype A (ACTCAGGT). Alignment of the sequences across species suggests that the $\mathrm{C}$ found in the $\mathrm{B}$ haplotype is the more common nucleotide, with only the horse and the yak (like Bos taurus in the Bovidae family) sharing the T with haplotype A. Although CREB, OCT1, and CEBP surround this site, MatInspector does not identify a transcription factor binding site that might be affected by the polymorphism.

It appears, therefore, that haplotype A, even though it is much more common in the breeds analyzed in this study, is unique across species and that haplotype B is more consistent with other species, especially the ruminants. Indeed, haplotype B $(\mathrm{G} / \mathrm{C} / \mathrm{C})$ is shared by goat, sheep, and water buffalo.
Analysis using the MatInspector program (Cartharius et al., 2005) suggests that the major transcription factor binding sites present in the regions around the 3 polymorphic sites, before selecting for factors known only to be expressed in mammary tissue, are HNF6 and OCTB (position 1), HAML and HOXF, (position 2), and CREB, HOXF, HOMF, PARF, CEBP, and OCTB (position 3). Haplotype A also presents many unique transcription factor binding sites not identified in haplotype $\mathrm{B}$ at one of the polymorphic positions (GFI1, HOXC, HOXF, EVI1), whereas haplotype B has only 1 unique site not identified in haplotype A (SRF). The identification of a novel site only reflects that the polymorphism has made the sequence more homologous to the consensus matrix for that site where one version (absent) falls below a threshold score ( 0.75 , optimized), and the other version is above it (present). Of these transcription factor binding sites, analysis suggests (Malewski and Zwierzchowski, 2002) that HOXF, OCTB, CEBP, and EVI1 are the most relevant to the expression of milk proteins.

Of course computer-aided analysis can only suggest potential transcription factor binding sites. Possibly the most relevant is HOXF, which has potential sites in 2 of the 3 positions but has a more optimal site (at position 1) in haplotype A. Similarly, haplotype A might favor binding of EVI1. In addition, it has been suggested that OCT1 (ATTTGCAT) may also bind to position 1 (Schild et al., 1994), although the C (bold) is replaced by $\mathrm{G}$ in both bovine haplotypes A and B: haplotype B may bind OCT1 preferentially as the G (underlined) in haplotype $\mathrm{A}$ is replaced by a $\mathrm{T}$.

\section{CONCLUSIONS}

In summary, haplotype A is the more common form seen in the bovine breeds studied and may potentially be favored from the standpoint of stronger potential transcription factor binding. However, haplotype B is much more consistent with other known $\kappa$-CN genes, and the results suggest that, at least in 1 mammary cell line, gene expression is stronger from this promoter form. It could be argued that the expression pattern may be different in bovine mammary cells, that the effects may have been more pronounced upon hormonal induction, that gene expression might not reflect protein expression, or that stronger expression of $\kappa-\mathrm{CN}$ may not be beneficial to overall milk characteristics, but this initial study does suggest that under these particular in vitro conditions, expression is favored by one allele over the other and that the haplotype should be investigated further with a larger number of animals to determine whether there is an association of haplotype with milk quality characteristics. The promoter A 
and B haplotypes do not appear to be associated with the coding region haplotypes $\mathrm{A}$ and $\mathrm{B}$, but this does not exclude the possibility that they are linked to another factor that is key to milk quality.

\section{ACKNOWLEDGMENTS}

This work was supported by Enterprise Ireland and by a Teagasc Walsh fellowship to A. F. Keating. Thanks to Benoit Houeix and Emma Holian (National University of Ireland, Galway) for assistance with the statistical analysis.

\section{REFERENCES}

Adachi, T., J. Y. Ahn, K. Yamamoto, N. Aoki, R. Nakamura, and T. Matsuda. 1996. Characterization of the bovine $\kappa$-casein gene promoter. Biosci. Biotechnol. Biochem. 60:1937-1940.

Alexander, L. J., A. F. Stewart, A. G. Mackinley, T. V. Kapelinskaya, T. M. Tkach, and S. I. Gorodetsky. 1988. Isolation and characterisation of the bovine $\kappa$-casein gene. Eur. J. Biochem. 178:395-401.

Bobe, G., D. C. Beitz, A. E. Freeman, and G. L. Lindberg. 1999. Effect of milk protein genotypes on milk protein composition and its genetic parameter estimates. J. Dairy Sci. 82:2797-2804.

Cartharius, K., K. Frech, K. Grote, B. Klocke, M. Haltmeier, A. Klingenhoff, M. Frisch, M. Bayerlein, and T. Werner. 2005. MatInspector and beyond: Promoter analysis based on transcription factor binding sites. Bioinformatics 21:2933-2942.

Debeljak, M., P. Frajman, T. Lenasi, M. Narat, A. Baldi, and P. Dovc. 2005 . Functional analysis of the bovine $\beta$ - and $\kappa$-casein gene promoters using homologous mammary gland derived cell line. Arch. Tierz. Dummerstorf 4:334-345.

Farrell, H. M., Jr., R. Jimenez-Florez, G. T. Bleck, E. M. Brown, J. E. Butler, L. K. Creamer, C. L. Hicks, C. M. Hollar, K. F. NgKwai-Hang, and H. E. Swaisgood. 2004. Nomenclature of the proteins of cows' milk-sixth revision. J. Dairy Sci. 87:1641-1674.

Gerencser, A., E. Barta, S. Boa, P. Kastanis, Z. Bosze, and C. B. Whitelaw. 2002. Comparative analysis on the structural features of the $5^{\prime}$ flanking region of $\kappa$-casein genes from six different species. Genet. Sel. Evol. 34:117-128.
Kaminski, S. 1996. DdeI RFLP at the $5^{\prime}$ region of bovine $\kappa$-casein gene. J. Appl. Genet. 37:173-178.

Kennedy, J., P. Dillon, K. O’Sullivan, F. Buckley, and M. Rath. 2003. Effect of genetic merit and concentrate supplementation on grass intake and milk production with Holstein-Friesian dairy. J. Dairy Sci. 86:610-621.

Lee, C. S., and T. Oka. 1992. Progesterone regulation of a pregnancyspecific transcription repressor to $\beta$-casein gene promoter in mouse mammary gland. Endocrinology 131:2257-2262.

Malewski, T., and L. Zwierzchowski. 2002. Genes expressed in cattle mammary gland - computational analysis of 5 -upstream sequences in search for factors conferring a tissue- and stage-specific transcription. Anim. Sci. Pap. Rep. 20:5-20.

Martin, P., M. Szymanowska, L. Zwierzchowski, and C. Leroux. 2002. The impact of genetic polymorphisms on the protein composition of ruminant milks. Reprod. Nutr. Dev. 42:433-459.

Marziali, A. S., and K. F. Ng-Kwai-Hang. 1986. Effects of milk composition and genetic polymorphism on coagulating properties of milk. J. Dairy Sci. 69:1793-1798.

Mercier, J. C., G. Brignon, and B. Ribadeau-Dumas. 1973. Primary structure of bovine $\kappa$-casein B. Complete sequence. Eur. J. Biochem. 35:222-235.

Mitchell, P. J., C. Wang, and R. Tjian. 1987. Positive and negative regulation of transcription in vitro: Enhancer-binding protein AP2 is inhibited by SV40 T antigen. Cell 50:847-861.

Ng-Kwai-Hang, K. F., J. F. Hayes, J. E. Moxley, and H. G. Monardes. 1984. Association of genetic variants of casein and milk serum proteins with milk, fat, and protein production by dairy cattle. J. Dairy Sci. 67:835-840.

Nierop Groot, M. N., H. O'Hara, R. J. FitzGerald, and R. P. Ross. 1995. Evaluation of allele-specific primers for rapid identification of bovine $\kappa$-casein genotypes by the polymerase chain reaction. Ir. J. Agric. Food. Res. 34:165-173.

Robitaille, G., M. Britten, J. Morisset, and D. Petitclerc. 2005. Polymorphism in the bovine $\kappa$-casein (CSN3) gene and the $5^{\prime}$ flanking region: Sequence analysis of CSN3 A and B alleles. Anim. Genet. $36: 184-185$.

Ron, M., O. Yoffe, E. Ezra, J. F. Medrano, and J. I. Weller. 1994. Determination of effects of milk protein genotypes on production traits of Israeli Holsteins. J. Dairy Sci. 77:1106-1113.

Schaar, J. 1984. Effects of $\kappa$-casein genetic variants and lactation number on the renneting properties of individual milks. J. Dairy Res. 51:397-406.

Schild, T. A., V. Wagner, and H. Geldermann. 1994. Variants within the $5^{\prime}$ flanking regions of bovine milk protein genes. I. $\kappa$-Caseinencoding gene. Theor. Appl. Genet. 89:116-120. 